\title{
Anti-proliferative effects of cucurmosin on human hepatoma HepG2 cells
}

\author{
JIEMING XIE ${ }^{1 *}$, WENZHONG QUE ${ }^{2 *}$, HUILI LIU ${ }^{3}$, MEI LIU $^{4}$, AIQIN YANG $^{1}$ and MINGHUANG CHEN ${ }^{5}$ \\ ${ }^{1}$ College of Pharmacy, Fujian Medical University; ${ }^{2}$ Department of Hematology and Rheumatology, The First Affiliated \\ Hospital of Fujian Medical University, Fujian; ${ }^{3}$ Zhangzhou Health Vocational College, Zhangzhou; \\ ${ }^{4}$ Department of Hematology, The Second Hospital of Yulin, Shanxi; ${ }^{5}$ The State Key Laboratory of Structural Chemistry, \\ Fujian Institute of Research on the Structure of Matter, Chinese Academy of Sciences, Fuzhou, P.R. China
}

Received June 3, 2011; Accepted September 16, 2011

DOI: $10.3892 / \mathrm{mmr} .2011 .605$

\begin{abstract}
We extracted cucurmosin (CUS) from the sarcocarp of Cucrubita moschata (pumpkin). Recently, a number of studies have indicated that CUS has cytotoxic properties and induces apoptosis in a number of human tumor cells. However, the detailed mechanisms are largely unknown. The aim of this study was to confirm CUS's anticancer activity on human hepatoma HepG2 cells in vitro and in vivo, and to elucidate the mechanism of its activity. MTT was used to detect the cytotoxic effects of CUS. Flow cytometry was used to analyze cell apoptosis and the cell cycle. Transmission electron microscopy was used to observe the morphology of apoptotic cells. Western blot analysis was performed to measure the protein expression of bax, bcl-2 and procaspase-3. The established orthotopic transplantation models of human hepatoma in NOD/SCID mice were tested for anticancer activities in vivo. The results showed that CUS inhibited the proliferation of HepG2 cells in vitro and in vivo. CUS induced apoptosis and arrested the cell cycle. In addition, CUS increased the protein expression of bax, but decreased the bcl- 2 and procaspase- 3 expression in HepG2 cells. Our data indicate that CUS has potential anticancer activity for human hepatoma, which can be attributed in part to its inhibition of proliferation and apoptosis, induced by decreasing the bcl-2:bax ratio and caspase-3 activation.
\end{abstract}

\section{Introduction}

Cucurmosin (CUS) is an active component extracted from the sarcocarp of Cucrubita moschata (pumpkin), a type of vegetable, which has long been used for medicinal purposes in China. The overall structure of CUS has been eluci-

Correspondence to: Dr Jieming Xie, College of Pharmacy, Fujian Medical University, 88 Jiaotong Road, Taijiang, Fuzhou, Fujian 350005, P.R. China

E-mail: xiejm2010@163.com

"Contributed equally

Key words: cucurmosin, human hepatoma, HepG2 cells, apoptosis dated (Fig. 1) and has been proved to be one of the type 1 ribosome-inactivating proteins (RIPs) (1-3). For a long time, the interest in RIP has been focused on developing antitumor drugs that selectively target tumor cells.

Studies in vitro have shown that CUS inhibits the proliferation of murine melanoma B16, lung adenocarcinoma cancer A549, human chronic myelogenous leukemia K562 cells and human pancreatic cancer PANC-1 cells (3-5); induces apoptosis of human PANC-1, HL60 and K562 cells (data not shown); and induces the differentiation of B16 cells (6).

Based on its cytotoxic activity against multiple human cancer cells through the induction of apoptosis and/or differentiation, we hypothesized that CUS is a candidate agent for human hepatoma treatment and/or chemoprevention. To confirm this hypothesis, the inhibitory effects of CUS on the growth of human hepatoma cells in vitro, the growth inhibition of human hepatoma in vivo and the mechanism of its activity were investigated in this experimental study.

\section{Materials and methods}

Reagents. CUS (99\% purity; molecular weight $27 \mathrm{kDa}$ ) was isolated and dissolved in normal saline (NS) and stored at $-80^{\circ} \mathrm{C}$ in the laboratory $(3.68 \mathrm{mg} / \mathrm{ml})$. RPMI-1640 cell culture medium, trypsin and fetal calf serum were purchased from Invitrogen (Carlsbad, CA, USA). DMSO and MTT were purchased from Sigma (St. Louis, MO, USA). Antibodies against bax, bcl-2, procaspase-3, $\beta$-actin and the secondary antibody were purchased from Santa Cruz Biotechnology (Santa Cruz, CA, USA). The Annexin V/PI-FITC kit and enhanced chemiluminesence (ECL) reagents were purchased from Beyotime Institute of Biotechnology (Haimen, China).

Cells and animals. HepG2 cells were purchased from the Cell Bank of Shanghai Institute of Cell Biology (Shanghai, China), maintained in RPMI-1640 culture medium plus $10 \%$ calf serum, $100 \mathrm{U} / \mathrm{ml}$ penicillin and $75 \mathrm{U} / \mathrm{ml}$ streptomycin at $37^{\circ} \mathrm{C}$ in a humidified atmosphere containing $5 \% \mathrm{CO}_{2}$. Four-week-old NOD/SCID male mice were purchased from SIBS (Shanghai, China). The maintainance, use and treatment of all animals in this study were in accordance with accepted standards of the Ethics Committee of ECNU. The experimental protocol was 

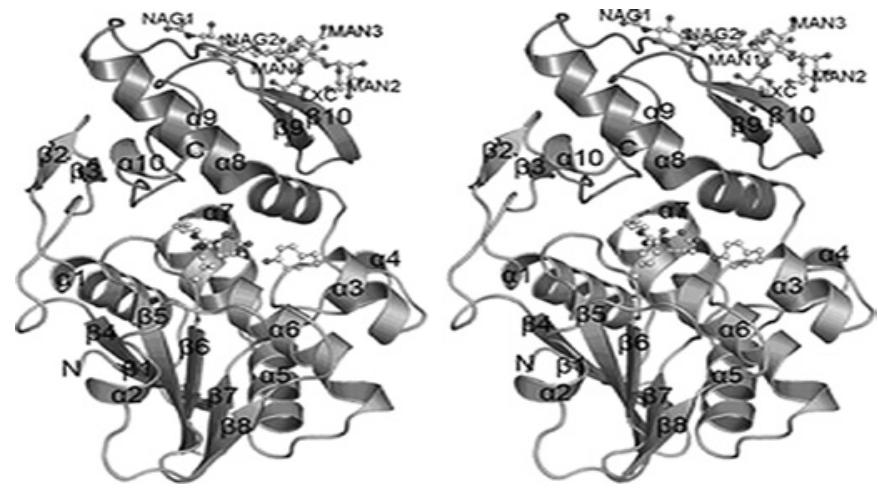

Figure 1. Overall structure of CUS in stereo view (3).

approved by the China Medical Experimental Animal Care Committee.

Cell viability assay. Cells in the exponential phase were seeded into 96-well plates, $100 \mu \mathrm{l}\left(1 \times 10^{5}\right.$ cells $\left./ \mathrm{ml}\right)$ per well. Then, various concentrations of CUS in $100 \mu \mathrm{l}$ culture medium were added and the final concentration in each well was 1, 2, 4, 8, 16, 32 and $64 \mu \mathrm{g} / \mathrm{ml}$, respectively. Each treatment was tested in tetrad wells and the control group was administered culture medium containing no drug. All of the above plates were placed in a $\mathrm{CO}_{2}$ humidified-atmosphere incubator at $37^{\circ} \mathrm{C}$ for $24,36,48,72$ and $96 \mathrm{~h}$. At the end of exposure, $20 \mu \mathrm{l} \mathrm{MTT}$ $(5 \mathrm{mg} / \mathrm{ml})$ was added to each well and the plates were incubated at $37^{\circ} \mathrm{C}$ for $4 \mathrm{~h}$. Then, all culture medium supernatant was removed from the wells and replaced with $200 \mu 1$ DMSO. The plates were agitated for $10 \mathrm{~min}$ so that all of the formazan that had been produced could be dissolved. The absorbance of each well was measured by standard enzyme-linked immunosorbant assay at $570 \mathrm{~nm}$. The cell viability was calculated based on the following formula: cell viability $(\%)=$ average A570 nm of treated group/average A570 nm of control group $\mathrm{x} 100 \%$.

Ultrastructure analysis using transmission electron microscopy (TEM). Following exposure to CUS, and pre-fixing with $2.5 \%$ glutaraldehyde and $2 \%$ paraformaldehyde at $4{ }^{\circ} \mathrm{C}$ for $12 \mathrm{~h}$, the cells were post-fixed with $1 \%$ osmium tetroxide, dehydrated in an ethanol series and embedded in Spurr Epon. Thin sections were stained with $4 \%$ uranyl acetate and $0.2 \%$ lead citrate and examined on a JEOL 200 EX II electron microscope (JEOL, Tokyo, Japan).

Cell cycle analysis. Cells were collected and washed twice in cold phosphate-buffered saline (PBS). The cells were fixed in $70 \%$ ethanol, treated with $100 \mathrm{mg} / 1$ RNase at $37^{\circ} \mathrm{C}$ for $30 \mathrm{~min}$ and stained with $50 \mathrm{mg} / 1$ propidium iodide (PI) (Sigma) for $30 \mathrm{~min}$ in the dark. Then, the percentage of cells in each phase of the cell cycle was detected and analyzed using ModFit software (Becton Dickinson, San Jose, CA, USA).

Annexin V/PI double staining assay. Cells were collected, washed twice in cold PBS and resuspended in $500 \mu \mathrm{l}$ binding buffer (Sigma). Annexin V (10 $\mu \mathrm{l})$ and PI solution (5 $\mu \mathrm{l})$ were added to the cell preparations, and incubation was carried out for $30 \mathrm{~min}$ in the dark at room temperature. Binding

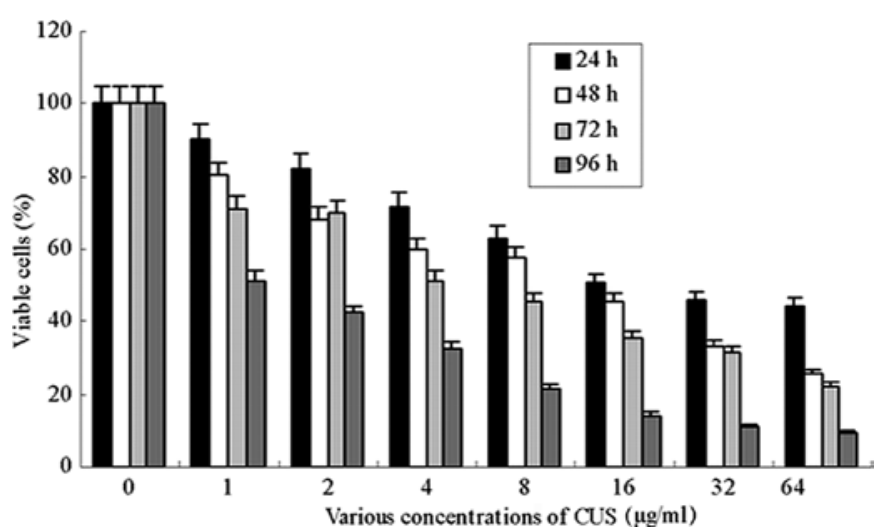

Figure 2. Effect of CUS on cell viability of HepG2 cells. HepG2 cells were incubated with various concentrations of CUS for 24, 48, 72 and $96 \mathrm{~h}$, and with medium without CUS as a control. All data were reported as the percent change compared to the solvent-only control group, which was regarded as $100 \%$ viability. Data are the means \pm SD of three independent experiments.

buffer $(400 \mu \mathrm{l})$ was then added to each tube and the samples were analyzed by FACScan flow cytometry equipped with CellQuest software (Becton Dickinson).

Western blot analysis. Briefly, the HepG2 cells were plated at a density of $2 \times 10^{5}$ cells/well. Following treatment, the cells were collected and lysed. The protein concentration was determined by the Lowry method using BSA as a standard. Equal amounts of protein were separated on $10 \%$ SDS-PAGE gels. The protein was then electrophoretically blotted onto polyvinylidene fluoride (PVDF) membranes. The membranes were first hybridized with primary antibodies and then with the secondary antibody. The immune blots were developed using the ECL system.

In vivo experiments. HepG2 cells $\left(1 \times 10^{8}\right)$ in $0.2 \mathrm{ml}$ NS were injected subcutaneously into the back of NOD/SCID mice. When the tumor reached $\sim 2 \mathrm{~cm}$ in diameter, the tumor tissue was cut into $1 \times 1 \times 1 \mathrm{~mm}$ sections and implanted into the livers of $50 \mathrm{NOD} / \mathrm{SCID}$ mice by using a trocar catheter and a pair of ophthalmologic forceps. The wound was occlusively treated by medical biological glue for hemostasis and closed. On the 7 th day following the establishment of the model, exploratory laparotomy was performed in all animals. The success rate of the model was $100 \%$. The 50 models were randomized into five groups: $0.25 \mathrm{mg} / \mathrm{kg}$ CUS group (CUS-1), $0.5 \mathrm{mg} / \mathrm{kg}$ CUS group (CUS-2), $1 \mathrm{mg} / \mathrm{kg}$ CUS group (CUS-3), positive group (25 mg/kg CTX group) and negative group (NS group). Five groups were administered the drug according to the above dose groups via tail intravenous injection every other day from the 10th to the 16th day. On the 24th day, half of the animals in each group were sacrificed. The body and tumor weight of these mice were detected. The remaining animals in each group were used to observe the survival time of tumor-bearing in the following assay. The tumor inhibitory rate $\%=(1-$ mean tumor weight of the drug group/mean tumor weight of the control group) $\mathrm{x} 100 \%$; the prolonged survival rate $\%=$ (mean days of survival of the treatment group/mean days of survival of the control group - 1) x $100 \%$. The survival time 
Table I. Comparison of the cell cycle distribution for all cell groups.

\begin{tabular}{lcccc}
\hline Treatment groups & Sub-G1 phase $(\%)$ & G0/G1 phase $(\%)$ & S phase $(\%)$ & G2/M phase $(\%)$ \\
\hline Control & $1.79 \pm 0.38$ & $34.46 \pm 4.98$ & $51.32 \pm 4.51$ & $12.74 \pm 1.96$ \\
CUS $2.5 \mu \mathrm{g} / \mathrm{ml}$ & $9.45 \pm 1.43^{\mathrm{a}}$ & $41.63 \pm 4.39^{\mathrm{a}}$ & $39.65 \pm 4.78^{\mathrm{a}}$ & $11.23 \pm 1.47$ \\
CUS $10 \mu \mathrm{g} / \mathrm{ml}$ & $11.23 \pm 2.72^{\mathrm{a}}$ & $56.53 \pm 5.85^{\mathrm{a}}$ & $23.93 \pm 3.75^{\mathrm{a}}$ & $9.55 \pm 1.84$ \\
CUS $40 \mu \mathrm{g} / \mathrm{ml}$ & $17.85 \pm 3.29^{\mathrm{a}}$ & $61.17 \pm 5.42^{\mathrm{a}}$ & $14.69 \pm 2.54^{\mathrm{a}}$ & $8.94 \pm 1.42$ \\
\hline
\end{tabular}

Cells were exposed to solvent-only (control) or CUS for $72 \mathrm{~h}$. Values are expressed as the percentage of the cell population in the G1, S and $\mathrm{G} 2 / \mathrm{M}$ phases of the cell cycle. Data are shown as the means $\pm \mathrm{SD}$ from at least three separate experiments. ${ }^{\mathrm{a}} \mathrm{p}<0.05$, significantly different from the control group.

was calculated from the day from the establishment of the model to mortality.

Statistical analysis. The results were expressed as the means $\pm \mathrm{SD}$. The significance of differences in multiple comparisons was determined using the Student's t-test. $\mathrm{P}<0.05$ was considered to be statistically significant.

\section{Results}

Cell viability. As shown in Fig. 2, the viable cell percentages relative to the control were $90.12 \pm 3.93,82.26 \pm 5.14,71.94 \pm 6.27$, $63.17 \pm 4.79,50.73 \pm 3.99,46.17 \pm 5.24$ and $44.43 \pm 6.11 \%$, respectively, when treated with various concentrations of CUS $(1,2$, $4,8,16,32$ and $64 \mu \mathrm{g} / \mathrm{ml}$ ) for $24 \mathrm{~h}$. The viable cell percentages relative to the control were $80.12 \pm 3.42,68.14 \pm 3.58,60.19 \pm 2.05$, $57.74 \pm 4.29,45.51 \pm 2.62,33.13 \pm 2.19$ and $25.45 \pm 2.77 \%$, respectively, when treated with various concentrations of CUS $(1,2$, $4,8,16,32$ and $64 \mu \mathrm{g} / \mathrm{ml}$ ) for $48 \mathrm{~h}$. The viable cell percentages relative to the control were $70.78 \pm 4.46,69.74 \pm 3.58,51.33 \pm 3.95$, $45.53 \pm 3.49,35.43 \pm 4.69,31.53 \pm 2.89$ and $21.95 \pm 4.71 \%$, respectively, when treated with various concentrations of CUS (1, 2, $4,8,16,32$ and $64 \mu \mathrm{g} / \mathrm{ml}$ ) for $72 \mathrm{~h}$. The viable cell percentages relative to the control were $51.36 \pm 1.28,42.41 \pm 1.71,32.63 \pm 0.29$, $21.73 \pm 1.17,14.23 \pm 0.79,11.15 \pm 1.21$ and $9.61 \pm 2.11 \%$, respectively, when cultured with various concentrations of CUS $(1,2$, $4,8,16,32$ and $64 \mu \mathrm{g} / \mathrm{ml}$ ) for $96 \mathrm{~h}$. The $\mathrm{IC}_{50}$ were $18.24 \pm 4.55$, $13.17 \pm 3.31,6.34 \pm 2.19$ and $1.27 \pm 0.37 \mu \mathrm{g} / \mathrm{ml}$, respectively, when HepG2 cells were treated with CUS for various durations (24, 48, 72 and $96 \mathrm{~h}$ ). The proliferation of HepG2 cells was markedly inhibited by CUS in a dose- and time-dependent manner.

Cell cycle analysis. To analyze the effect of CUS on HepG2 cell growth and apoptosis, the cell cycle distribution was determined by flow cytometry. As shown in Table I, when HepG2 cells were treated with CUS at $0,2.5,10$ and $40 \mu \mathrm{g} / \mathrm{ml}$ for $48 \mathrm{~h}$, the percentage of cells in the sub-G1 phase increased from $1.79 \pm 0.38$ to $9.45 \pm 1.43,11.23 \pm 2.72$ and $17.85 \pm 3.29 \%$, respectively. This increase was accompanied by an increase in the number of G0/G1 phase cells and a decrease in the cell population in the $\mathrm{S}$ phase.

Analysis of apoptosis. We used flow cytometry with Annexin V and PI staining to detect apoptosis induced by CUS. Under the same conditions mentioned above, the number of Annexin $\mathrm{V}^{+}$ cells was increased in the CUS-treated HepG2 cells in a

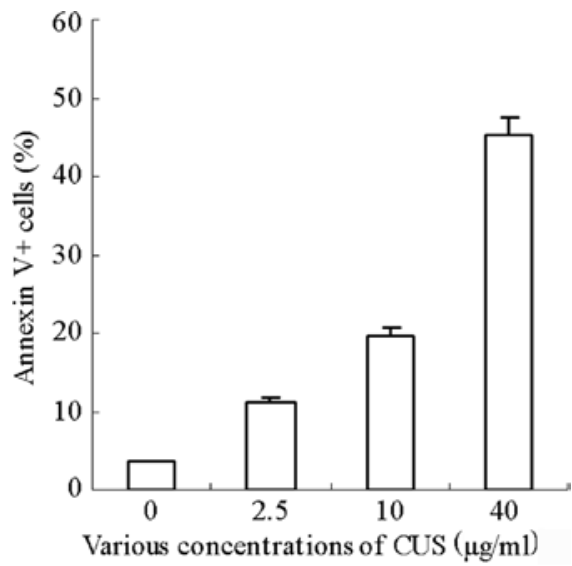

Figure 3. Apoptosis measured by Annexin V-FITC/PI staining. HepG2 cells were treated with the indicated concentrations of CUS $(0,2.5,10$ and $40 \mu \mathrm{g} / \mathrm{ml}$ ) for $72 \mathrm{~h}$, stained with Annexin V-FITC and propidium iodide (PI) and analyzed by flow cytometry. The apoptotic cells were determined by counting the percentage of Annexin $\mathrm{V}^{+}$, $\mathrm{PI}^{-}$cells and the percentage of Annexin $\mathrm{V}^{+}, \mathrm{PI}^{+}$cells. The results are expressed as the means $\pm \mathrm{SD}$ of three independent experiments.

concentration-dependent manner compared to the untreated control cells (Fig. 3). This is consistent with our findings of an increase in small DNA fragments in the sub-G1 phase (Table I).

Ultrastructure analysis. TEM is considered the gold standard to confirm apoptosis. When the cells were exposed to $10 \mu \mathrm{g} / \mathrm{ml}$ CUS for $48 \mathrm{~h}$, the apoptotic characteristics, such as chromatin condensation, nuclear shrinkage and fragmentation, as well as apoptotic bodies, were observed (Fig. 4). Ultrastructure changes provided further evidence for CUS-induced apoptosis.

Expression of apoptosis-related proteins. Western blotting was used to detect the levels of bcl-2 and bax during the CUS-induced apoptosis. As shown in Fig. 5, up-regulation of bax and downregulation of bcl-2 in cells treated with CUS was observed. Next, we examined whether caspase-3 was activated during the induction of apoptosis by CUS. The level of procaspase-3 (32 $\mathrm{kDa}$ precursor) was significantly reduced in CUS-treated cells compared to the level of the control cells, which suggest that the activation of caspase- 3 occurs in CUS-treated cells.

Tumor growth in vivo. To investigate the antitumor activities of CUS in vivo, NOD/SCID mice were used to establish 
$\mathbf{A}$

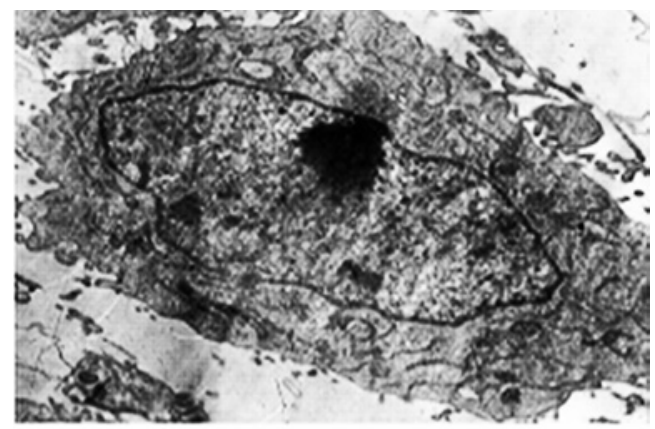

B

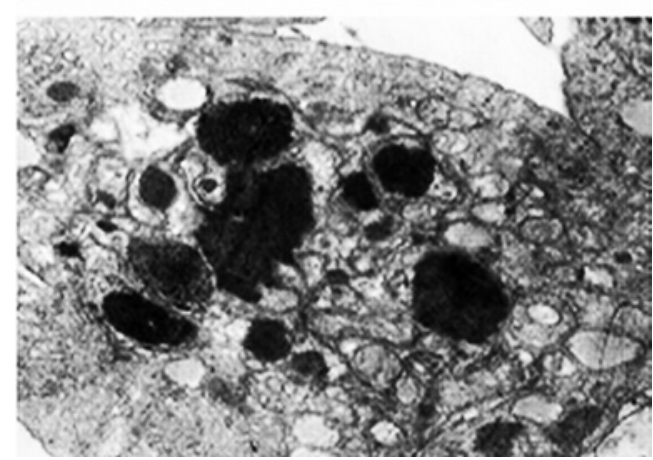

Figure 4. Effect of CUS on the ultrastructure of HepG2 cells. Cells were exposed to solvent-only (control) or CUS, then analyzed using transmission electron microscopy. (A) Control; (B) $10 \mu \mathrm{g} / \mathrm{ml}$ CUS for $48 \mathrm{~h}$ (magnification, $\mathrm{x} 8,000)$.
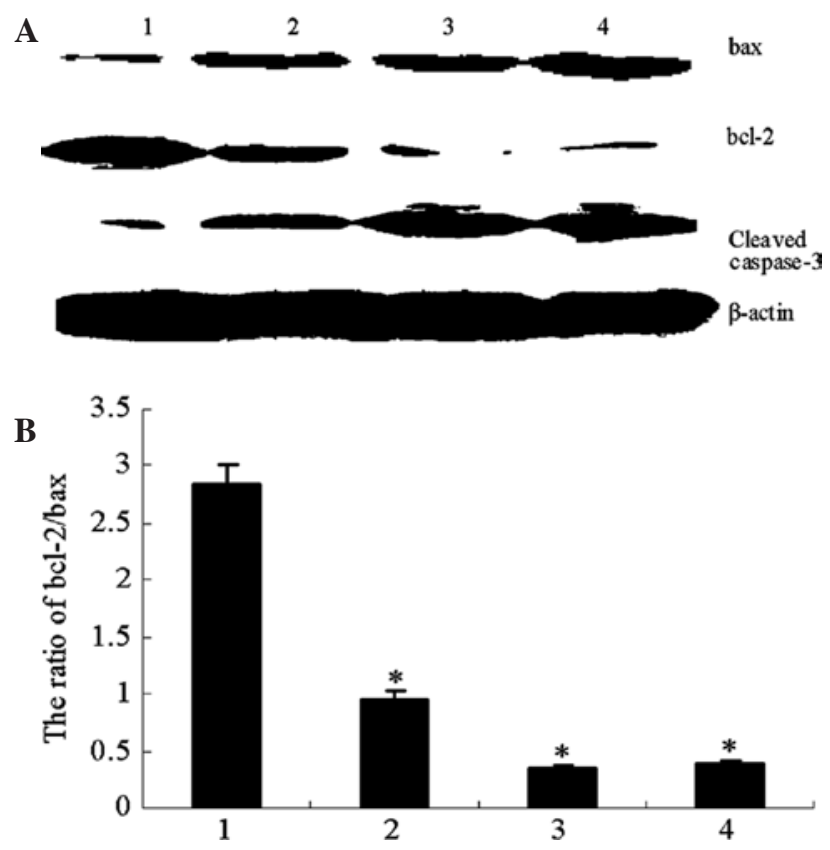

Figure 5. Effect of CUS on the expression of apoptosis-related proteins. (A) HepG2 cells were treated with CUS for $72 \mathrm{~h}$. Total cell lysates were prepared and Western blot analysis was performed using antibodies against bax, bcl-2, procaspase- 3 and $\beta$-actin. (B) The ratios of Bcl-2/Bax are shown by the histograms. " $p<0.05$ vs. control. Lanes 1-4 represent HepG2 cells treated with $0,2.5,10$ and $40 \mu \mathrm{g} / \mathrm{ml}$ CUS, respectively.

a human hepatoma in situ transplantation model. As shown in Table II, there was no significant difference in the weight of mice among these five groups prior to the establishment of the model ( $p>0.05)$, indicating that the mice of the five groups were comparable in vivo. Compared to the NS group,

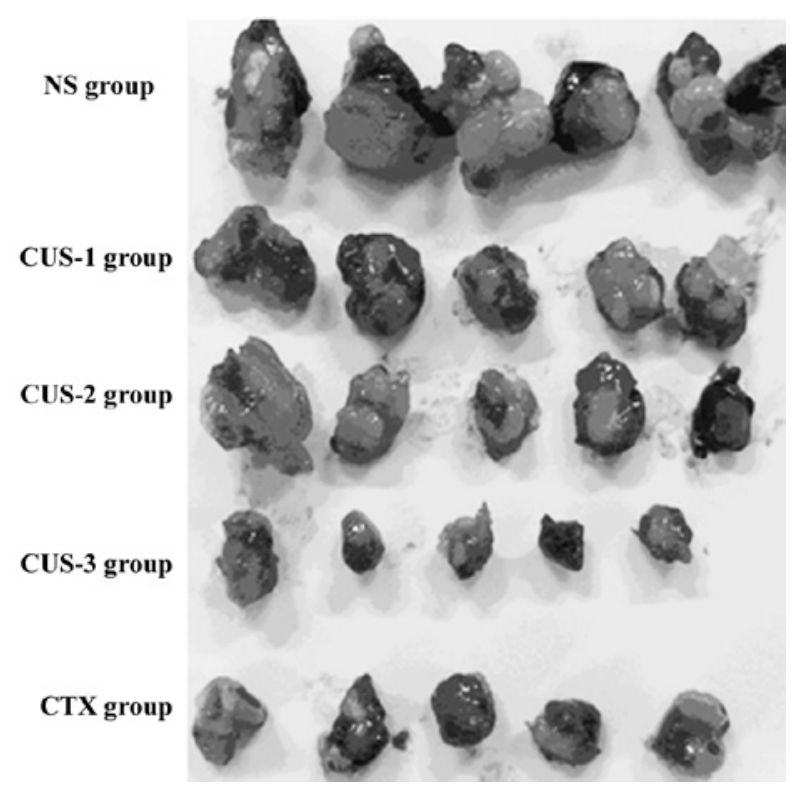

Figure 6. Antitumor effect of CUS on HepG2 cells in NOD/SCID mice. Dose-dependent effects of CUS on tumor volume and tumor weight in human hepatoma HepG2 cells in an in situ transplantation model of NOD/ SCID mice.

the weights of the tumors of the CUS-1, CUS-2, CUS-3 and CTX groups were reduced significantly $(\mathrm{p}<0.01)$, particularly in the CUS-3 group, with a tumor inhibitory rate of $78.4 \%$. The tumor inhibitory rate of the CTX, CUS- 2 and CUS-1 groups was $69.8,66.3$ and $53.7 \%$, respectively (Table II and Fig. 6). There was no significant difference in the weight of mice among all CUS groups and the NS group ( $p>0.05$ ). Compared to the NS groups, the weight of mice in the CTX group decreased significantly $(\mathrm{p}<0.05)$.

Mean survival and life prolonging rate. Tumor-bearing survival of the CUS-1-3 groups was prolonged, and the difference was significant among all the CUS groups and the NS and CTX groups $(\mathrm{p}<0.05)$, particularly in the CUS-3 group. Survival of the CTX group was not significantly prolonged compared to the NS group ( $\mathrm{p}>0.05$; Table III). There was no evident change in weight, appetite and behavior following administration of CUS at all concentrations, and there was no treatment-related mortality.

\section{Discussion}

Our previous study indicated that CUS exerted antitumor activities by inducing apoptosis in numerous tumor cell lines (data not shown). However, there have been no studies on the anticancer activity of CUS in human hepatoma cells in vitro and in vivo. The cell line was valuable for the rapid screening of potential anticancer agents and the elucidation of the mechanism of their activity (7). In the present study, the HepG2 cell line was used as a cellular model of hepatoma for drug screening. We confirmed that CUS exhibited strong dose- and time-dependent anticancer activity in human hepatoma HepG2 cells in vitro.

Next, the results of flow cytometry showed that CUS induced significant cell cycle arrest at the G0/G1 interface, 
Table II. Body weight of mice prior to treatment and post treatment, weight of tumors and the inhibition rate (means \pm SD; $\mathrm{n}=5$ ).

\begin{tabular}{|c|c|c|c|c|c|}
\hline \multirow[t]{2}{*}{ Treatment groups } & \multirow[t]{2}{*}{$\mathrm{n}$} & \multicolumn{2}{|c|}{ Weight of mice $(\mathrm{g})$} & \multirow[t]{2}{*}{ Weight of tumors (g) } & \multirow[t]{2}{*}{ Inhibition $(\%)$} \\
\hline & & Pre-treatment & Post-treatment & & \\
\hline NS control & 5 & $19.3 \pm 1.3$ & $24.8 \pm 1.5$ & $0.57 \pm 0.04$ & - \\
\hline CTX & 5 & $19.1 \pm 1.6$ & $14.4 \pm 1.9^{\mathrm{a}}$ & $0.18 \pm 0.02^{b}$ & 69.8 \\
\hline CUS-1 & 5 & $19.7 \pm 0.9$ & $23.6 \pm 2.4$ & $0.28 \pm 0.04^{\mathrm{b}}$ & 53.7 \\
\hline CUS-2 & 5 & $19.9 \pm 0.7$ & $24.2 \pm 2.3$ & $0.22 \pm 0.02^{\mathrm{b}}$ & 66.3 \\
\hline CUS-3 & 5 & $19.2 \pm 0.6$ & $23.4 \pm 2.7$ & $0.12 \pm 0.03^{b}$ & 78.4 \\
\hline
\end{tabular}

${ }^{a} \mathrm{p}<0.05$ vs. NS group or CUS groups; ${ }^{b} \mathrm{p}<0.05$ vs. NS group.

Table III. Mean survival time and life prolonging rate of each group (means $\pm \mathrm{SD})$.

\begin{tabular}{lccc}
\hline Treatment & $\mathrm{n}$ & $\begin{array}{c}\text { Mean survival } \\
\text { time (days) }\end{array}$ & $\begin{array}{c}\text { Life prolonging } \\
\text { rate }(\%)\end{array}$ \\
\hline Control & 5 & $39.1 \pm 2.7$ & - \\
CTX & 5 & $39.9 \pm 3.2$ & 2.1 \\
CUS-1 & 5 & $45.2 \pm 2.9^{\mathrm{a}}$ & 19.8 \\
CUS-2 & 5 & $48.6 \pm 3.4^{\mathrm{a}}$ & 24.3 \\
CUS-3 & 5 & $53.1 \pm 2.3^{\mathrm{a}}$ & 35.7 \\
\hline
\end{tabular}

${ }^{\mathrm{a}} \mathrm{p}<0.05$ vs. control.

suggesting it as a mechanism for the antiproliferative effect of CUS. These results were consistent with our previous reports that CUS induced apoptosis and G0/G1 arrest (6). The inhibition of cell growth and the cell cycle arrest induced by CUS led in turn to apoptosis, as confirmed by Annexin V-FITC/PI staining and the sub-G1 peak assessed by flow cytometry. In addition, the apoptosis-inducing effect of CUS on HepG2 cells was also evidenced by TEM. The apoptotic morphological features, such as chromatin condensation, nuclear shrinkage and fragmentation, as well as apoptotic bodies, were observed in cells after treatment of CUS.

To test the mechanism of CUS-induced apoptosis, we first investigated the effects of CUS on the levels of the bcl-2 family. Accumulating data indicate that the bcl-2 family significantly regulates apoptosis either as an activator bax or as an inhibitor bcl-2, and the ratio of bcl-2/bax is also regarded as a key factor in regulating the apoptotic process (8-10). In this study, we found the ratio of bcl-2/bax was decreased in the process of apoptosis induced by CUS. In addition, caspases are known to be required for apoptosis induced by various stimuli $(11,12)$. Among caspases, caspase- 3 is thought to be the main effector and a significant step in the execution phase of apoptosis (13). The present study showed that CUS-induced apoptosis of HepG2 was also related to the activation of caspase-3.

However, it was essential that a suitable animal model was used to investigate the in vivo efficacy of potential anticancer agents (14). In the present study, NOD/SCID mice were used to establish a human hepatoma HepG2 cell in situ transplantation model to study the antitumor activities of CUS in vivo. The results showed that the weight of the tumor in all CUS groups was reduced significantly compared to the NS group $(\mathrm{p}<0.01)$, tumor-bearing survival was significantly prolonged compared to the NS group $(\mathrm{p}<0.05)$, and there was no significant change in the weight of mice among all CUS groups and the NS group ( $p>0.05)$. However, the survival of mice in the CTX group was not significantly prolonged compared to the NS group ( $p>0.05)$, and the weight of mice decreased significantly compared to the other groups $(\mathrm{p}<0.05)$. The results of the in vivo study suggest that CUS exhibits potent antitumor activities in vivo and relatively low toxicity in hepatoma HepG2 cells.

In conclusion, in vitro and in vivo studies have demonstrated that CUS is a promising agent in inhibiting the growth potential of hepatoma HepG2 cells. It may affect hepatoma progression as a result of its effects on cell cycle progression and apoptosis by reducing the ratio of bcl-2/bax and the activation of caspase-3. However, determination of the optimal dosage in vivo and other related mechanisms is necessary in order to establish the scientific basis for the possible application of CUS in the treatment of hepatoma.

\section{Acknowledgements}

This study was supported by the National Nature Science Fund of China (30772587), the Provincial Nature Science Fund of Fujian (C0510012) and the Scientific Foundation of Fujian Medical University (FJGXY04019).

\section{References}

1. Chen MH, Ye X, Cai J, et al: Crystallization and preliminary crystallographic study of cucurmosin, a ribosome-inactivating protein from the sarcocarp of Cucurbita moschata. Acta Cryst 56: 665-666, 2000.

2. Shi XL, Zhou EX, Ye XM, et al: Molecular replacement studies of cucurmosin from Cucurbita moschata: structure homology with trichosanthin. Chin J Struct Chem 22: 165-168, 2003.

3. Hou X, Meehan EJ, Xie J, et al: Atomic resolution structure of cucurmosin, a novel type 1 ribosome-inactivating protein from the sarcocarp of Cucurbita moschata. J Struct Biol 164: 81-87, 2008.

4. Sun JC, Xie JM, Zhang KZ, et al: The effect of cucurmosin and ST1571 on K562 cell growth in vitro. J Fujian Med Univ 42: 30-32, 2008.

5. Xu CS, Huang HG, Chen MH, et al: Cytotoxic and chemosensitivity enhancement effect of cucurmosin on pancreatic cancer cell line PANC-1 in vitro. Chin J Gen Surg 18: 233-236, 2009.

6. Xie JM, Yu CX, Chen MH, et al: Diferentiation-inducing efect of cucurmosin on B16 melanoma cells. Chin Pharmacol Bull 22: 329-332, 2006 . 
7. Wang XJ, Wei YQ, Yuan SL, et al: Potential anticancer activity of tanshinone IIA against human breast cancer. Int J Cancer 116: 799-807, 2005

8. Adams JM and Cory S: The Bcl-2 protein family: arbiters of cell survival. Science 281: 1322-1326, 1998

9. Nomura M, Shimizu S, Ito T, et al: Apoptotic cytosol facilitates Bax translocation to mitochondria that involves cytosolic factor regulated by Bcl-2. Cancer Res 59: 5542-5548, 1999.

10. Thees S, Hubbard GB, Winckler J, et al: Specific alteration of the $\mathrm{Bax} / \mathrm{Bcl} 2$ ratio and cytochrome $\mathrm{c}$ without execution of apoptosis in the hippocampus of aged baboons. Restor Neurol Neurosci 23: $1-9,2005$.
11. Krepela E: Cysteine proteinases in tumor cell growth and apoptosis. Neoplasma 48: 332-349, 2001.

12. Budihardjo I, Oliver H, Lutter M, et al: Biochemical pathways of caspase activation during apoptosis. Ann Rev Cell Dev Biol 15: 269-290, 1999

13. Oliver FJ, de la Rubia G, Rolli V, et al: Importance of poly(ADPribose) polymerase and its cleavage in apoptosis. Lesson from an uncleavable mutant. J Biol Chem 273: 33533-33539, 1998.

14. Heindryckx F, Colle I and Van VH: Experimental mouse models for hepatocellular carcinoma research. Int J Exp Pathol 90: 367-386, 2009. 